\title{
Phosphate Removal from Wastewaters Using a Weak Anion Exchanger Prepared from a Lignocellulosic Residue
}

\author{
T.S. ANIRUDHAN*, B.F.NOELINE AND D.M. MANOHAR
}

Department of Chemistry, University of Kerala, Kariavattom, Trivandrum- 695 581, India

Supporting Information

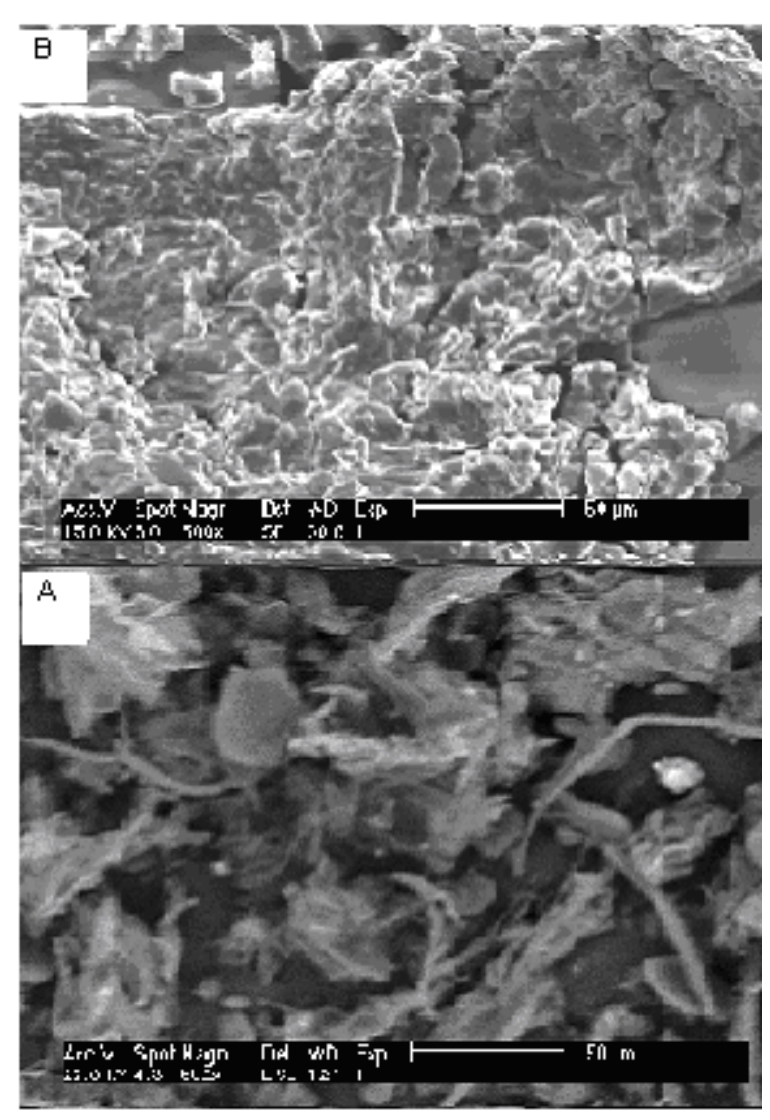

Scanning Electron Micrographs of BS (A) and BS-DMAHP (B) 